\title{
INCLUSÃO DIGITAL PARA IDOSOS: EXPERIÊNCIA DE FORMAÇÃO DOCENTE EM PROJETO DE EXTENSÃO NO CAMPUS NATAL ZONA - NORTE
}

\section{RESUMO}

Este artigo tem como objetivo apresentar experiências vividas por meio do Projeto de Extensão intitulado "Inclusão Digital para Terceira Idade", que é coordenado por dois professores do IFRN e sistematizado por alunos do Curso de Licenciatura em Informática do Campus Natal - Zona Norte. O projeto consiste em um curso introdutório de Informática oferecido para moradores da Zona Norte de Natal/RN com idade superior a 50 anos. Observa-se que o projeto tem atingido importância significativa, pois permite atender a uma demanda social no entorno do IFRN, bem como colocar os alunos na condição de aprendizes da docência em formação específica que trata da aprendizagem do adulto.

Palavras-chave: Aprendizagem do adulto; Formação docente; Curso de Informática.

\section{INTRODUÇÃO}

A inclusão da terceira idade na Informática é vista principalmente como uma possibilidade de convivência com o mundo contemporâneo e tudo o que ele oferece, favorecendo as relações familiares, sociais, comerciais e tantas outras (BIZELLI et al, 2009, p. 6). Este artigo versa sobre uma reflexão das atividades do Projeto de Extensão intitulado "Inclusão Digital na Terceira Idade", realizado no Campus Natal - Zona Norte do IFRN. Uma das atividades de iniciação à docência da disciplina Metodologia do Ensino de Informática, do curso de Licenciatura em
Informática, é o desenvolvimento do referido projeto, que foca na aprendizagem do adulto e, consequentemente, na sua inclusão digital. Com isso, os licenciandos têm a rica experiência de atuar junto a idosos e suas peculiaridades para aprendizagem, particularmente no que se refere à apropriação da tecnologia.

\section{A PRÁTICA DE ENSINO NA LICEN- CIATURA EM INFORMÁTICA}

A matriz curricular atual do Curso de Licenciatura em Informática do IFRN apresenta a Prática de Ensino dividida em duas disciplinas: Meto- 
dologia do Ensino de Informática I (50 período) e Metodologia do Ensino de Informática II (60 período). Em ambas as disciplinas, a ementa consiste na elaboração, execução e avaliação de proposta pedagógica para ensino de Informática no ensino fundamental, médio e técnico (IFRN, 2012). A primeira disciplina trabalha o ensino de microinformática e a segunda o ensino de sistemas de informação e/ou sistemas de computação. Ambas as disciplinas têm sido ministradas pelos dois autores deste artigo: um deles atua no Núcleo Didático-Pedagógico e o outro no Núcleo Específico da Licenciatura em Informática. Diversas atividades compõem a disciplina, como seminários e provas de desempenho, mas a principal é a realização da prática de ensino em sala de aula.

Como a primeira disciplina trata especificamente do ensino de microinformática, abordando, portanto, conceitos básicos e introdutórios do uso do microcomputador como ferramenta de trabalho, pesquisa e entretenimento, foi verificada a possibilidade de que os graduandos pudessem realizar a prática de ensino ministrando aulas de Informática para a comunidade. Sendo assim, os alunos desenvolvem um projeto de extensão, como atividade avaliativa da disciplina, para a oferta de um curso de Informática Básica para pessoas com idade igual ou superior a 50 (cinquenta) anos, residentes na Zona Norte de Natal/RN, onde o campus está localizado. Dessa forma, os alunos têm a oportunidade de conhecer e exercitar, na prática, atividades docentes como planejamento, preparação de material didático, regência e avaliação. Por outro lado, essa atividade propicia uma série de benefícios para os participantes, como conhecer melhor o IFRN e sua função social, se integrar com outras pessoas da mesma faixa etária e que têm dificuldades semelhantes no uso do microcomputador, e, principalmente, ter conhecimento e segurança para utilizar o microcomputador em sua vida pessoal.

\section{O CURSO DE INFORMÁTICA PARA A COMUNIDADE}

Para a oferta do curso de Informática tratado neste artigo, a primeira atividade dos alunos da disciplina Metodologia do Ensino de Informática I consiste no desenvolvimento de um projeto, sob a orientação dos professores da disciplina, apresentando justificativa, objetivos, metodologia, recursos didáticos, conteúdos e cronograma do curso. Este projeto é parte avaliativa da disciplina mencionada e é formalizado junto à Coordenação de Extensão do IFRN/Campus Natal - Zona Norte. Portanto, a cada semestre letivo, o projeto é atualizado com a inserção de novos alunos (instrutores do curso), alterações na carga horária e na ementa, assim como outras mudanças que forem necessárias.

O curso de Informática é composto por três módulos: Introdução à Microinformática, Sistema Operacional Windows 7 e Fundamentos de Internet. A cada módulo, os alunos se dividem e se revezam na condução das aulas: um deles ministra o conteúdo teórico/prático e os demais atuam como monitores da turma, verificando as dificuldades que os participantes têm nas atividades práticas e esclarecendo dúvidas gerais de maneira mais próxima. Todas as aulas são realizadas no Laboratório de Informática da Licenciatura.

No primeiro módulo, os participantes têm as primeiras noções sobre Informática, como aprender a ligar e desligar o computador corretamente, identificar as diferenças e os diversos exemplos de hardware e software, conhecer e praticar a utilização adequada do teclado e do mouse, dentre outras. No segundo módulo, os participantes aprendem a usar as principais funções do sistema operacional Windows 7, como área de trabalho, gerenciamento de arquivos e pastas, acessórios (calculadora, bloco de notas, ferramenta de desenho, etc.), dentre outros. No terceiro módulo, os participantes aprendem os fundamentos básicos da Internet, dentre eles: as principais funções de um browser (navegador), download de arquivos, utilização de e-mails, buscas, etc.

\section{RELATO DE EXPERIÊNCIA DO PRO- JETO DE EXTENSÃO}

No semestre letivo 2013.2, foi realizada a primeira oferta do curso de extensão. A turma da Prática de Ensino em Microinformática era composta por apenas três graduandos. Dessa forma, apenas uma turma do curso de Informática pôde ser aberta, tendo ao todo 28 participantes e carga horária total de 24 horas. Cada módulo foi conduzido por uma dupla: um aluno ministrando as aulas e o outro tirando as dúvidas dos participantes nas atividades práticas. Os participantes apresentaram bastante interesse em conhecer e utilizar o que o microcomputador pode proporcionar. Para os licenciandos, instrutores do curso, foi uma experiência bastante enriquecedora. Eles sabiam que precisariam ter cuidados metodológicos e pedagógicos específicos para a turma em questão. Foi muito significativo para eles perceber as intensas diferenciações 


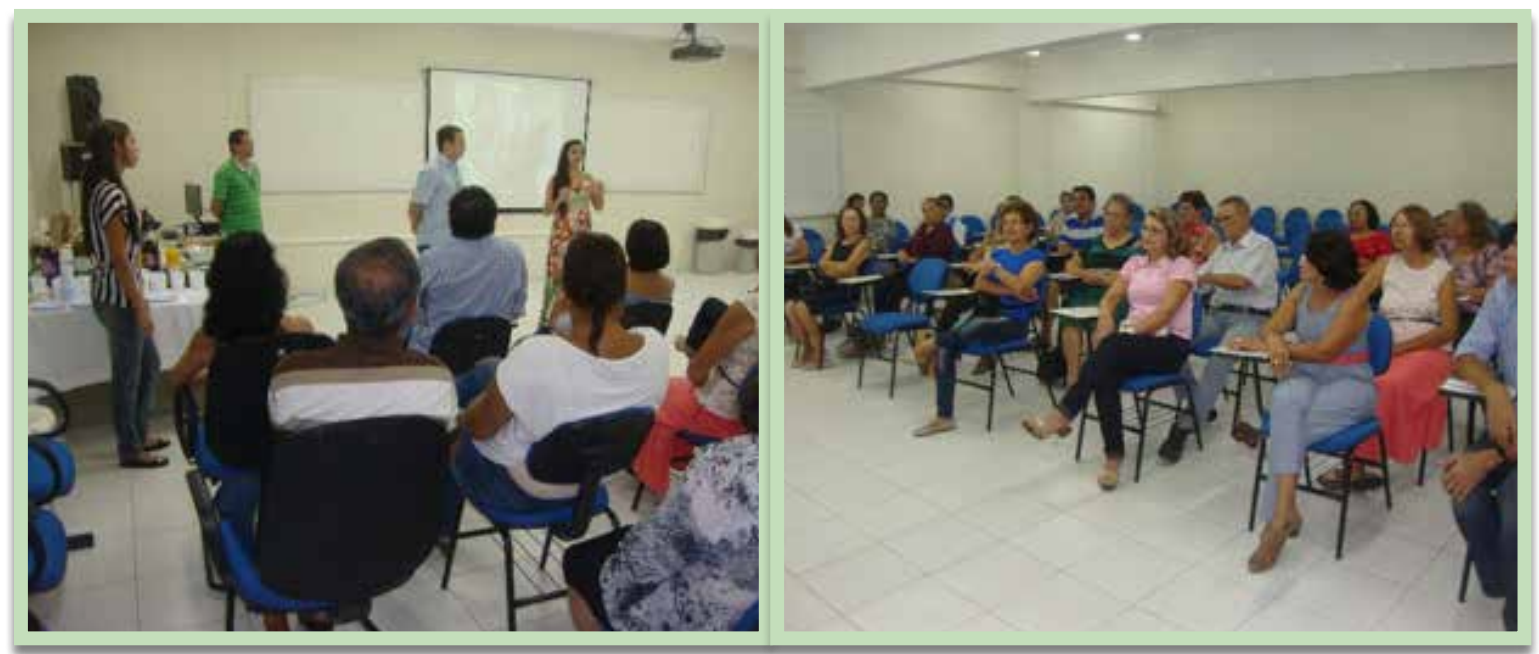

Figura 1 - Momento de confraternização, coordenadores, instrutores e participantes falam sobre a importância do curso.

dessa modalidade de ensino. Ao final do curso, os participantes se mostraram bastante satisfeitos com o que aprenderam, comprovando isso em confraternização realizada no último encontro, conforme mostram as imagens apresentadas na Figura 1.

No semestre letivo 2014.1, a turma da primeira disciplina de prática de ensino tem 6 (seis) alunos. Após a entrega do projeto por parte dos alunos, foram abertas as inscrições para duas novas turmas do curso de Informática: uma com aulas nas terças e sextas, das 16 às $18 \mathrm{~h}$, e outra com aulas aos sábados, das 8 às $12 \mathrm{~h}$. Para cada uma das duas turmas foram abertas 25 vagas, que foram todas ocupadas, mesmo com apenas três dias de inscrições. A Figura 2 apresenta imagens de uma das turmas do curso no Laboratório de Informática.
A carga horária do curso foi aumentada para 40 horas, mas a ementa permanece a mesma, o que propicia mais tempo aos participantes para as atividades práticas propostas. Além disso, na oferta atual do curso, estão presentes três instrutores em cada turma, melhorando assim a condução da aula e o esclarecimento de dúvidas. Percebe-se que os futuros licenciados em Informática têm a oportunidade de vivenciar a docência com um público diferente do público adolescente. $\mathrm{O}$ ambiente de aprendizagem que tenta-se construir com as pessoas adultas no curso de extensão é permeado de liberdade e incentivo para cada indivíduo falar de sua história, ideias, opinião, compreensão e conclusões. O diálogo conduz a essência do relacionamento pedagógico e a experiência é o elemento impulsionador da aprendizagem.

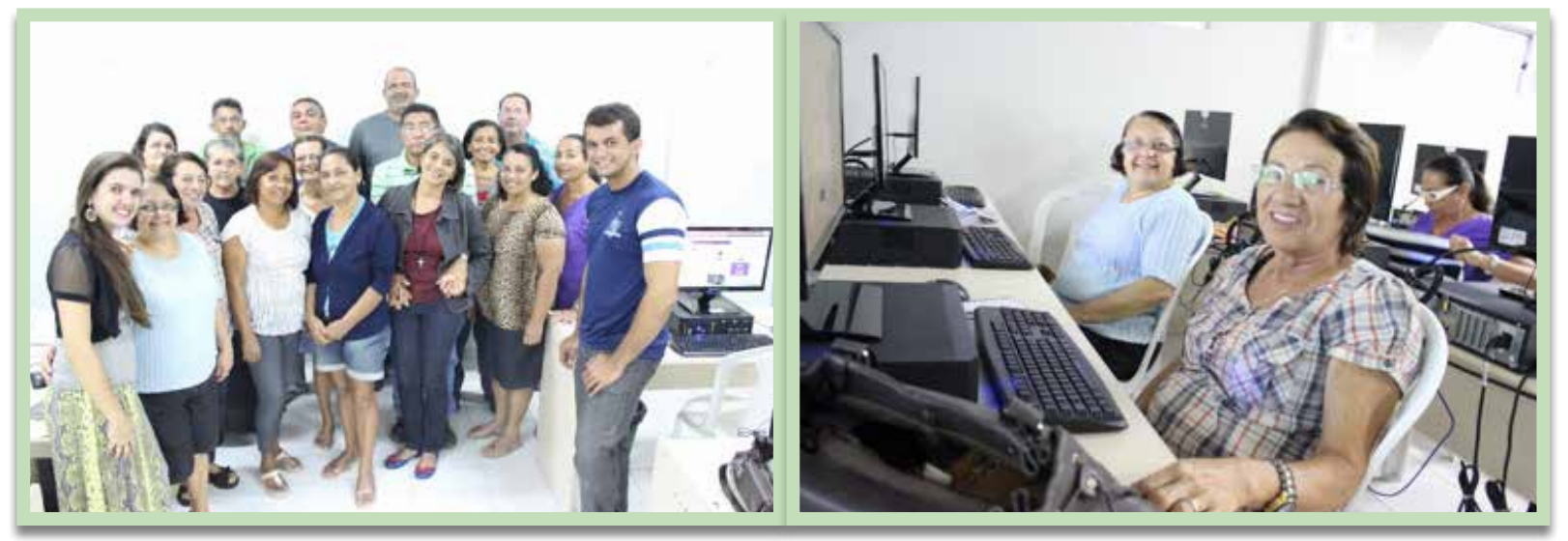

Figura 2 - Coordenadora, aluno instrutor e participantes no Laboratório de Informática. 


\section{CONCLUSÕES}

Observa-se com a experiência do projeto de extensão que os licenciandos em Informática têm a possibilidade de atuar de maneira inicial em ações docentes voltadas ao idoso, que possui aprendizagem cognitiva diferenciada, com foco em processos motivacionais e de autoestima. Nesse caso, a dialogicidade é um procedimento fundamental para a condução do processo de ensino e aprendizagem.

A comunicação é um fator imprescindível para manutenção e aumento do círculo social e, portanto, da promoção da autoestima. Estes fatores justificam a importância da criação de alternativas de interação para a inserção do idoso em atividades, como, por exemplo, o uso do computador e suas ferramentas de comunicação e informação, que o estimulem, integrem e possam ampliar seus objetivos de vida. (SALES et al, 2007, p. 6).

Mostra-se que o projeto de extensão apresentado neste artigo atinge seus objetivos tanto no que se refere à formação inicial à docência dos licenciandos do IFRN, bem como à necessidade social da comunidade em torno do Campus Natal - Zona Norte.

\section{REFERÊNCIAS}

IFRN: Instituto Federal de Educação, Ciência e Tecnologia do Rio Grande do Norte, 2012. Projeto Pedagógico do Curso Superior de Licenciatura em Informática na Modalidade Presencial. Disponível em: http://portal.irn.edu.br. Acesso em: 23 abr. 2014.

SALES, M. B.; GUAREZI, R. C.; FIALHO, F. A. P. Infocentro para Terceira Idade: Relato de Experiência de Aprendizagem por Pares. Colabor@ - Revista Digital da CVA - Ricesu, v. 4, n. 13, mar. 2007.

BIZELLI, M. H. S. S.; BARROZO, S.; TANAKA, J. S.; SANDRON, D. C. Informática para a Terceira Idade - Características de um Curso Bem Sucedido. Revista Ciência em Extensão, v. 5, n. 2, p. 4-14, 2009. 